\title{
Thoracic Malignancies and Pulmonary Nodules in Patients under Evaluation for Transcatheter Aortic Valve Implantation (TAVI): Incidence, Follow Up and Possible Impact on Treatment Decision
}

\author{
Lars Henning Schmidt ${ }^{1{ }^{*}}$, Benedikt Vietmeier ${ }^{1 \oplus}$, Gerrit Kaleschke ${ }^{2}$, Christoph Schülke ${ }^{3}$, \\ Dennis Görlich ${ }^{4}$, Christoph Schliemann ${ }^{1}$, Torsten Kessler ${ }^{1}$, Arik Bernard Schulze ${ }^{1}$, \\ Boris Buerke ${ }^{3}$, Andreas Kuemmel ${ }^{5}$, Michael Thrull', Rainer Wiewrodt ${ }^{1}$, \\ Helmut Baumgartner ${ }^{2}$, Wolfgang E. Berdel ${ }^{1}$, Michael Mohr ${ }^{1}$ \\ 1 Department of Medicine A, Hematology, Oncology and Pneumology, University Hospital Münster, \\ Münster, Germany, 2 Department of Cardiovascular Medicine, Division of Adult Congenital and Valvular \\ Heart Disease, University Hospital Münster, Münster, Germany, 3 Department of Clinical Radiology, \\ University Hospital of Münster, Münster, Germany, 4 Institute of Biostatistics and Clinical Research, \\ Westfälische Wilhelms-Universität Münster, Münster, Germany, 5 Pulmonary Division, Department of \\ Medicine III, Johannes Gutenberg University Medical Center, Mainz, Germany \\ - These authors contributed equally to this work. \\ * larshenning.schmidt@ukmuenster.de
}

Citation: Schmidt LH, Vietmeier B, Kaleschke G, Schülke C, Görlich D, Schliemann C, et al. (2016) Thoracic Malignancies and Pulmonary Nodules in Patients under Evaluation for Transcatheter Aortic Valve Implantation (TAVI): Incidence, Follow Up and Possible Impact on Treatment Decision. PLOS ONE 11(5): e0155398. doi:10.1371/journal.pone. 0155398

Editor: Andreas-Claudius Hoffmann, West German Cancer Center, GERMANY

Received: January 19, 2016

Accepted: April 28, 2016

Published: May 12, 2016

Copyright: @ 2016 Schmidt et al. This is an open access aricle distributed under the terms of the Creative Commons Attribution License, which permits unrestricted use, distribution, and reproduction in any medium, provided the original author and source are credited.

Data Availability Statement: All relevant data are within the paper and its Supporting Information files. Data are available at the Institute of Biostatistics and Clinical Research, Westfallische Wilhelms-Universität Münster.

Funding: NSCLC research in the authors' laboratory is funded by the Innovative Medizinische Forschung Münster University (IMF: I-SC110818), Deutsche Krebshilfe e. V. (107888; 109666), Open Access Publication Fund of University of Muenster, and Wilhelm Sander-Stiftung (2009.041.1). W.E.B. is

\section{Abstract}

\section{Background}

Transcatheter aortic valve implantation (TAVI) has become the treatment of choice in patients with severe aortic valve stenosis who are not eligible for operative replacement and an alternative for those with high surgical risk. Due to high age and smoking history in a high proportion of TAVI patients, suspicious findings are frequently observed in pre-procedural chest computer tomography (CCT).

\section{Methods}

CCT scans of 484 consecutive patients undergoing TAVI were evaluated for incidentally discovered solitary pulmonary nodules (SPN).

\section{Results}

In the entire study population, SPN $\geq 5 \mathrm{~mm}$ were found in 87 patients (18\%). These patients were compared to 150 patients who were incidentally collected from the 397 patients without SPN or with SPN $<5 \mathrm{~mm}$ (control group). After a median follow-up of 455 days, lung cancer was diagnosed in only two patients. Neither SPN $\geq 5 \mathrm{~mm}(p=0.579)$ nor $\mathrm{SPN}>8$ $\mathrm{mm}(\mathrm{p}=0.328)$ were significant predictors of overall survival. 
supported by Deutsche Forschungsgemeinschaft DFG EXC 1003 Cells in Motion - Cluster of Excellence.

Competing Interests: The authors have declared that no competing interests exist.

\section{Conclusions}

Despite the high prevalence of SPNs in this single center TAVI cohort lung cancer incidence at midterm follow-up seems to be low. Thus, aggressive diagnostic approaches for incidentally discovered SPN during TAVI evaluation should not delay the treatment of aortic stenosis. Unless advanced thoracic malignancy is obvious, the well documented reduction of morbidity and mortality by TAVI outweighs potentially harmful delays regarding further diagnostics. Standard guideline-approved procedure for SPN can be safely performed after TAVI.

\section{Introduction}

Lung cancer remains one of the world's most common and most lethal cancer types [1]. To reduce incidence and mortality rates of lung cancer, both improved smoking prevention programs and early clarification of suspicious radiologic findings are essential. To improve lung cancer screening and prevention, the National Lung Screening Trial (NLST) Research Team evaluated, whether low-dose computed tomography based screening programs for patients at risk can reduce lung cancer mortality [2]. With regard to this evaluation, computer tomography based screening can be recommended for well-defined subgroups, such as heavy smokers in between 55 to 74 years [3]. Compared to colorectal cancer screening for example, improved prognostic effects of mass screening might therefore not be indicated for patients lacking specific risk constellations. Moreover, the most efficient diagnostic approach for routine screening is also not clarified, yet. One major clinical problem of computed tomography based screening is related to a high sensitivity but a rather low specificity of newly detected SPN to indicate malignant tumors [4].

Among suspicious radiologic findings especially solitary pulmonary nodules (SPN), lymphadenopathy (LAP) and pleural effusions (PE) are of clinical relevance. With regard to the size, pulmonary lesions with a diameter of less than $3 \mathrm{~cm}$ and which are completely surrounded by parenchyma are defined as SPN, whereas the term "tumor mass" refers to lesions above $3 \mathrm{~cm}$ in size $[5,6]$. The differential diagnosis includes both benign lesions (e.g. hamartoma or granuloma [5,7]) and malignant primary tumors [6] or secondary tumors [8]. Often, SPN are found incidentally on routine chest X-rays. One study ( $\mathrm{n}=25.529$ patients above 35 years) found a prevalence of SPN of $2 \%$ in chest X-rays [9]. In this study the number of incidentally discovered SPN on CT scans was even higher with 17\% [9]. Published incidence rates for incidentally discovered SPN on chest CT scans and the number of diagnosed lung cancer cases are summarized in Table 1.

On the basis of nodule size and risk profile (low-risk patient $v s$. high-risk patient), the Fleischner Society published guidelines for the follow-up and clinical management of incidentally discovered SPN [10]. At present, the diagnostic work-up covers positron emission tomography $[11,12,13]$, transbronchial needle aspiration $[14,15,16]$, transthoracic needle biopsies $[17,18]$ and surgical intervention $[19,20]$. In case of low probability for malignant transformation, CT surveillance strategies are favored [6,10,21], with the potential risk of delayed onset of treatment (Fig 1). Of interest, chest X-rays should never be used to exclude SPN [9].

Due to rising life expectancy in Germany (http://www.destatis.de; Federal Statistical Office of Germany), incidence rates of degenerative valvular heart diseases are rising, too [22] Therapeutically, transcatheter aortic valve implantation (TAVI) has become the treatment of choice 
Table 1. The incidence of incidentally discovered SPN (cases on chest computer tomographies) and the number of diagnosed lung cancer cases.

\begin{tabular}{|c|c|c|c|c|c|}
\hline Author & Study patients (n) & Age (years) & Study population & SPN (\%) & Lung cancer (\%) \\
\hline Onuma et al. 2006 [34] & 503 & 66 & Patients with suspected coronary artery disease & 16.7 & 0.8 \\
\hline Haller et al. 2006 [39] & 166 & 64 & Patients with suspected coronary artery disease & n.e.* & 1.2 \\
\hline Müller et al. 2007 [35] & 259 & 64 & Patients after coronary artery bypass grafting surgery & 3.5 & 0.4 \\
\hline Burt et al. $2008[36]$ & 459 & 65 & Patients with suspected coronary artery disease & 28 & n.e.* \\
\hline Machaalany et al. $2009[37]$ & 966 & 58 & Patients with suspected coronary artery disease & $23^{* *}$ & 0.3 \\
\hline Gómez-Sáez et al. 2014 [9] & 2427 & 66 & non-high-risk population & 17 & n.e.* \\
\hline Stachon et al. $2015[38]$ & 374 & 80 & Patients under evaluation for TAVR & 4.3 & n.e.* \\
\hline Schmidt et al. 2016 & 484 & 82 & Patients under evaluation for TAVR & 18 & 0.6 \\
\hline
\end{tabular}

${ }^{*}$ n.e. $=$ not evaluable.

** granulomata included.

doi:10.1371/joumal.pone.0155398.t001

in patients with severe aortic valve stenosis who are not eligible for operative replacement $[23,24]$. Evaluation of the TAVI candidates is a multidisciplinary process [25]. Pre-procedural

TAVI evaluation requires invasive ascending and descending aortography and or CT angiography [26]. In line with the up-coming of this technique, the number of incidentally discovered SPN in pre-procedural CT scans has risen.

Here we present single center data upon the prevalence, clinical follow-up and possible impact on therapeutic decision of incidentally discovered SPN and thoracic malignancies in patients under evaluation for transcatheter aortic valve implantation.

\section{Methods}

\section{Study population}

Before data collection, approval from the joint Ethical Committee of the Faculty of Medicine of the Westfalian Wilhelms-University Münster and the Physicians Chamber of Westfalia-Lippe was obtained (application number: 2015-037-f-S). Since the data collection was retrospective, written consent was considered as not necessary. Patient information was anonymized and deidentified prior to analysis. For all included patients, TAVI evaluation was performed at the Department of Cardiovascular Medicine, Division of Adult Congenital and Valvular Heart Disease, University Hospital Münster, Germany. To assess the overall incidence of suspicious radiologic findings in our study collective, an overall screening for solitary pulmonary nodules (SPN), lymphadenopathy (LAP) and pleural effusions (PE) was performed in 484 consecutive patients. SPN $\geq 5 \mathrm{~mm}$ were found in 87 patients (18\%). From the remaining 397 patients without SPN or with SPN $<5 \mathrm{~mm}, 150$ patients were incidentally collected for comparison (control group, Fig 2). Baseline characteristics of the two groups (i.e. patients without SPN or SPN $<4$ $\mathrm{mm} v s$. patients with SPN $\geq 5 \mathrm{~mm}$ ) are demonstrated in Table 2. Computed power of $57.2 \%$ for both groups of patients was calculated using Statistical Analysis System (SAS Institute, Cary, NC, USA).

\section{Radiological CT imaging}

CT Angiography (CTA) was performed at the Department of Clinical Radiology using dual source 64 and 128 slice CT scanners (Somatom Definiton and Somatom Definition Flash, Siemens AG, Medical Solutions, Forchheim, Germany) with a tube voltage of $120 \mathrm{kV}$ and a collimation of $64 / 128 \times 0.6 \mathrm{~mm}$ using an attenuation-based tube current modulation (CARE 


\section{Malignant probability \\ - Smoking status \\ - Work exposures \\ - Nodule size \\ - Shape \\ - Location \\ - Predictive models}
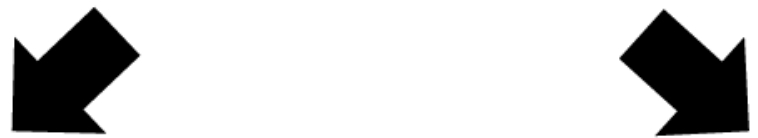

\section{$\downarrow$ Probability}

\section{CT \\ surveillance strategies}

Fig 1. Diagnostic strategies for incidentally discovered solitary pulmonary nodules (adapted from: Gould et al. 2013). doi:10.1371/joumal.pone.0155398.g001

dose4DTM, Siemens AG, Medical Solutions, Forchheim, Germany) to reduce radiation exposure.

Adapted to the patient's constitution and renal function $60-100 \mathrm{ml}$ i.v. contrast agent (Imeron 370, Bracco Imaging, Milano, Italy) were administered at a constant injection rate of $3-4 \mathrm{ml} / \mathrm{sec}$. Following bolus triggered start $(+140 \mathrm{HU}$, measured in the ascending aorta) images of the aortic root are acquired ECG-gated with a dose modulation, reducing the tube current between $80 \%$ and $20 \%$ of the R-R-cycle to $20 \%$. Subsequently the whole thoracoabdominal aorta including the inguinal arteries is acquired in one helical scan without ECGsynchronization.

All images were reconstructed in transverse orientation with a slice thickness of $1 \mathrm{~mm}$ and an increment of $0.6 \mathrm{~mm}$ for further evaluation. The ECG-gated dataset of the aortic root was additionally reconstructed in $10 \%$ steps, covering the whole R-R-cycle. 


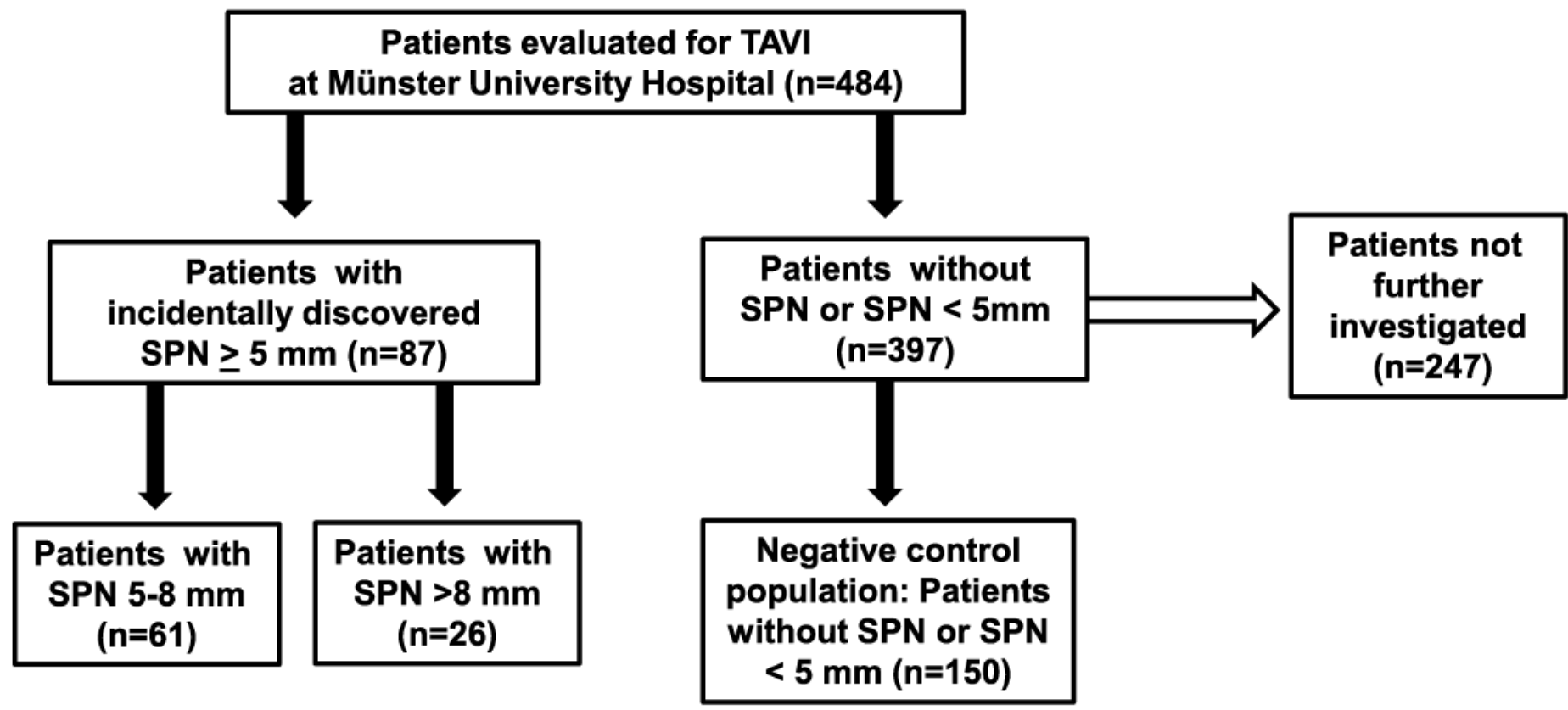

Fig 2. Study collective and tested clinical subgroups. The flow diagram demonstrates the selection of the tested subgroups ( ${ }^{*}$ control group includes both patients without detected SPN and those patients with SPN<5mm).

doi:10.1371/joumal.pone.0155398.g002

\section{Statistical Analysis}

The study population was described by standard descriptive statistical measures. For categorical variables, absolute and relative frequencies are reported. For continuous variables median and interquartile range (IQR) are reported, respectively. To compare both tested groups (i.e. patients without SPN or SPN $<5 \mathrm{~mm} v s$. patients with SPN $\geq 5 \mathrm{~mm}$ ) p-values for continuous parameters were calculated using Mann-Whitney-U-test and likewise for categorical variables Chi-square test or Fisher's exact test were applied, respectively. Similar, associations of clinicopathological parameters with SPN were tested using two-sided Fisher's exact test. Univariate overall survival analysis was performed using the Kaplan-Meier method and Log-rank tests. A multivariable Cox proportional hazard model was fitted using a forward step-wise variable selection (inclusion criteria: p-value of the likelihood ratio test $\leq 0.05$ ) to identify independent prognostic factors for overall survival. We considered potential prognostic factors that are tolerably complete (less than ten missing values, and with at least ten cases), to prevent statistical problems emerging from low sample size and extreme values. Patients with missing values in the cofactors were excluded from the analysis.

All statistical tests were performed as exploratory analyses on a local significance level of 0.05 . Since multiplicity adjustment was not carried out, no distinct overall significance level was ascertained. Hence, our findings may be used to set up new hypotheses. The statistical software SPSS (SPSS Statistics, Version 22.0 released 2013, IBM Corp., Armonk, NY) was used for all analyses.

\section{Results}

\section{Study collectives and patient selection}

Prevalence of SPN $\geq 5 \mathrm{~mm}$ on pre-procedural CT scans was $18 \%(\mathrm{n}=87)$ in the 484 patients, who were evaluated for TAVI eligibility at Münster University Hospital. Median age of the 
Table 2. Baseline characteristics of patients under TAVI evaluation with complete follow-up data $(n=237$ patients).

\begin{tabular}{|c|c|c|c|}
\hline & $\begin{array}{l}\text { Patients with SPN } \geq 5 \mathrm{~mm} \\
\quad(\mathrm{n}=87)\end{array}$ & $\begin{array}{l}\text { Patients without SPN or SPN }<5 \mathrm{~mm} \\
\qquad(\mathrm{n}=150)\end{array}$ & $\begin{array}{l}\text { p-values* for the comparison of both } \\
\text { tested groups }\end{array}$ \\
\hline \multicolumn{4}{|l|}{ Clinical parameters } \\
\hline Median age, years (Q1-Q3) & $83(77-87)$ & $82(78-86)$ & 0.571 \\
\hline Male gender, $\mathrm{N}(\%)$ & $37(43 \%)$ & $63(42 \%)$ & 0.937 \\
\hline \multicolumn{4}{|l|}{ Respiratory parameters } \\
\hline Smoking history N(\%) & $26(52 \%)$ & $47(38 \%)$ & 0.096 \\
\hline Median FEV1\% (Q1-Q3) & $78 \%(62 \%-94 \%)$ & $77 \%(64 \%-97 \%)$ & 0.380 \\
\hline \multicolumn{4}{|l|}{ Cardiologic parameters } \\
\hline LVEF, N(\%) & & & 0.148 \\
\hline$>55 \%$ & $61(72 \%)$ & $89(60 \%)$ & \\
\hline $45-54 \%$ & $6(7 \%)$ & $21(14 \%)$ & \\
\hline $30-44 \%$ & $13(15 \%)$ & $21(14 \%)$ & \\
\hline$<30 \%$ & $5(6 \%)$ & $17(12 \%)$ & \\
\hline $\begin{array}{l}\text { Median aortic valve } \\
\text { Area, } \mathrm{cm}^{2}(\mathrm{Q} 1-\mathrm{Q} 3)\end{array}$ & $0.6(0.5-0.8)$ & $0.6(0.5-0.8)$ & 0.966 \\
\hline TAVI performed, $\mathrm{N}(\%)$ & $70(81 \%)$ & $133(89 \%)$ & 0.082 \\
\hline \multicolumn{4}{|l|}{ Radiologic parameters } \\
\hline $\begin{array}{l}\text { Solitary pulmonary nodule, } \\
N(\%)\end{array}$ & & & $<0.0001$ \\
\hline$<5 \mathrm{~mm}$ & $0(0 \%)$ & $44(29 \%)$ & \\
\hline $5-8 \mathrm{~mm}$ & $61(70 \%)$ & $0(0 \%)$ & \\
\hline$>8 \mathrm{~mm}$ & $26(30 \%)$ & $0(0 \%)$ & \\
\hline Lymphadenopathy, N(\%) & $18(21 \%)$ & $48(32 \%)$ & 0.061 \\
\hline Pleural effusions, N(\%) & $15(17 \%)$ & $31(21 \%)$ & 0.520 \\
\hline Previous malignancy, N(\%) & $20(23 \%)$ & $39(26 \%)$ & 0.605 \\
\hline $\begin{array}{l}\text { Lung cancer diagnosis, } \\
\mathrm{N}(\%)\end{array}$ & $2(3 \%)$ & $0(0 \%)$ & 0.342 \\
\hline $\begin{array}{l}\text { Median follow-up, days } \\
\text { (Q1-Q3) }\end{array}$ & $406(233 ; 603)$ & $495(307 ; 859)$ & 0.012 \\
\hline
\end{tabular}

* p-values for the comparison of both tested groups (i.e. patients without SPN or SPN $<5 \mathrm{~mm}$ vs. patients with SPN $\geq 5 \mathrm{~mm}$ ).

For continuous parameters Mann-Whitney-U-test and for categorical variables Chi-square test or Fisher's exact test, respectively were applied.

doi:10.1371/joumal.pone.0155398.t002

entire study population was 82 years and 202 were male (42\%). Of interest, $n=111$ patients (23\%) had a malignant disease in the past and 3 patients were diagnosed for lung cancer following pre-procedural evaluation. All identified lung cancer patients were male smokers and had suspicious radiologic findings (i.e. patient \#1: SPN of $16 \mathrm{~mm}$ size; patient \#2: SPN of $21 \mathrm{~mm}$ size and lymphadenopathy; patient \#3: No SPN, but tumor mass of $6.2 \mathrm{~cm} \mathrm{x} 4 \mathrm{~cm}$ and lymphadenopathy). On last contact, all of them were still alive. However, TAVI was only performed on patient \#1 and on patient \#2.

For further diagnostic and prognostic analyses all those patients with incidentally discovered SPN $\geq 5 \mathrm{~mm}(\mathrm{n}=87)$ and $\mathrm{n}=150$ patients either without SPN or with $\mathrm{SPN}<5 \mathrm{~mm}$ (serving as the control population) were chosen (computed power: $57.2 \%$ ). Depending on the size of $\mathrm{SPN}, \mathrm{n}=61$ patients had SPN of $5-8 \mathrm{~mm}$ and $\mathrm{n}=26$ patients had SPN of $>8 \mathrm{~mm}$ size. Of the identified three lung cancer patients, only two patients had SPN by definition. Even though patient \#3 was also diagnosed with lung cancer, this patient was excluded from further statistical analyses due to the initial discovery of a "tumor mass" in the pre-procedural CT scan. 
Baseline characteristics for both tested study collectives (in total $\mathrm{n}=237$ patients: $\mathrm{n}=150$ patients without SPN or SPN $<5 \mathrm{~mm} v s . \mathrm{n}=87$ patients with $\mathrm{SPN} \geq 5 \mathrm{~mm}$ ) are summarized in Table 2. Regarding equal distribution of the two tested study collectives, no significant difference was found for the evaluated variables (e.g. age, gender or smoking history). Since the SPN size was command variable, a significant difference was found $(\mathrm{p}<0.0001)$.

\section{Clinical associations for identified SPN}

For the 237 study patients associations of clinical and respiratory parameters with suspicious radiologic findings (i.e. SPN $\geq 5 \mathrm{~mm}$, SPN $>8 \mathrm{~mm}$, LAP and PE) were investigated. Here, smoking history was positively associated with SPN $>8 \mathrm{~mm}(\mathrm{p}=0.033)$. Suspicious lymphadenopathy was found more often for patients below 80 years in contrast to patients above 80 years $(39 \%$ vs. $23 \% ; \mathrm{p}=0.013)$ and for men in contrast to women $(36 \% v s .22 \% ; \mathrm{p}=0.019)$. For all other tested variables no other relevant correlations with SPN, LAP or PE were found (all p $>0.05$; Table 3 ).

\section{Univariate prognostic effects}

Using Log-rank test, prognostic impact of SPN $\geq 5 \mathrm{~mm}$ and of SPN $\geq 8 \mathrm{~mm}$ in patients under TAVI evaluation with complete follow-up data $(\mathrm{n}=237$ patients) was investigated. Neither for SPN $\geq 5 \mathrm{~mm}$ nor for SPN $\geq 8 \mathrm{~mm}$ prognostic effects were found in these univariate analyses (all $p>0.05$, Table 4 and Fig 3 ). In addition, prognostic analyses were also performed for suspicious lymphadenopathy ( $p>0.05$; Table 4 and Fig 3 ) and pleural effusions $(\mathrm{p}=0.042$; Table 4 and Fig 3).

\section{Multivariate prognostic effects}

Cox proportional hazards models for comparison with established prognostic factors was used to identify prognostic impact in a multivariate setting. Included variables were: gender (male (ref.) $v s$. female), age ( $<80$ years (ref.) $v s . \geq 80$ years), left ventricular ejection fraction (both as continuous variable and as categorical variable ( $\mathrm{LVEF}<45 \%$ (ref.) $v s$. $\mathrm{LVEF} \geq 45 \%$ )), previous malignancy (no previous malignancy (ref.) $v s$. previous malignancy), solitary pulmonary nodules (no SPN (ref.) $v s$. SPN $\geq 5 \mathrm{~mm}$ and all others (ref.) $v s$. SPN $>8 \mathrm{~mm}$ ), lymphadenopathy (no LAP (ref.) $v s$. LAP) and pleural effusions (no PE (ref.) $v s$. PE).

As shown before in the univariate analyses, $\mathrm{SPN} \geq 5 \mathrm{~mm}$ or SPN $>8 \mathrm{~mm}$ were not identified as independent prognostic factors ( $p \geq 0.05$; Table 5$)$. However, left ventricular ejection fraction was found to be of prognostic relevance for overall survival $(\mathrm{HR}[95 \% \mathrm{CI}]=2.194$

Table 3. Correlations of clinical and respiratory parameters with suspicious radiologic findings (i.e. SPN, LAP and PE) for patients under TAVI evaluation with complete follow-up data ( $n=237$ patients).

\begin{tabular}{|c|c|c|c|c|}
\hline & \multicolumn{4}{|c|}{ p-values according to Fisher's exact test } \\
\hline & SPN $\geq 5 \mathrm{~mm}(\mathrm{n}=87)$ & $\mathrm{SPN}>8 \mathrm{~mm}(\mathrm{n}=26)$ & LAP $(n=66)$ & $\operatorname{PE}(n=46)$ \\
\hline \multicolumn{5}{|l|}{ Clinical parameters } \\
\hline Age ( $<80$ years $v s . \geq 80$ years) & 0.667 & 0.510 & 0.013 & 0.053 \\
\hline Sex (male vs. female) & 1.000 & 0.097 & 0.019 & 0.621 \\
\hline \multicolumn{5}{|l|}{ Respiratory parameters } \\
\hline Smoking history (non-smokers vs. smokers) & 0.126 & 0.033 & 0.741 & 0.414 \\
\hline FEV $1 \%$ (FEV $\geq 80 \%$ vs. FEV $1<80 \%$ ) & 0.741 & 0.318 & 0.727 & 0.401 \\
\hline Previous malignancy & 0.643 & 0.632 & 0.180 & 1.000 \\
\hline
\end{tabular}

doi:10.1371/joumal.pone.0155398.t003 
Table 4. Prognostic analysis for suspicious radiologic findings (i.e. SPN, LAP and PE) in patients under TAVI evaluation with complete follow-up data $(n=237$ patients).

\begin{tabular}{|c|c|c|c|c|}
\hline & \multicolumn{4}{|c|}{ p-value according to log rank test } \\
\hline & $\mathrm{SPN} \geq 5 \mathrm{~mm}(\mathrm{n}=87)$ & $\mathrm{SPN}>8 \mathrm{~mm}(\mathrm{n}=26)$ & LAP $(n=66)$ & $\operatorname{PE}(n=46)$ \\
\hline All patients, full study collective & 0.579 & 0.328 & 0.982 & 0.042 \\
\hline \multicolumn{5}{|l|}{ Subgroup: Clinical parameters } \\
\hline \multicolumn{5}{|l|}{ Age } \\
\hline$<80$ years & 0.268 & 0.382 & 0.824 & 0.015 \\
\hline$\geq 80$ years & 0.179 & 0.521 & 0.798 & 0.257 \\
\hline \multicolumn{5}{|l|}{ Sex } \\
\hline male & 0.227 & 0.677 & 0.959 & 0.140 \\
\hline female & 0.716 & 0.057 & 0.984 & 0.214 \\
\hline \multicolumn{5}{|l|}{ Subgroup: Respiratory parameters } \\
\hline \multicolumn{5}{|l|}{ Smoking } \\
\hline never-smokers & 0.206 & 0.383 & 0.575 & 0.954 \\
\hline smokers & 0.347 & 0.579 & 0.645 & 0.083 \\
\hline \multicolumn{5}{|l|}{ FEV1\% } \\
\hline FEV $1 \geq 80 \%$ & 0.663 & 0.799 & 0.824 & 0.040 \\
\hline FEV $1<80 \%$ & 0.468 & 0.969 & 0.712 & 0.991 \\
\hline \multicolumn{5}{|l|}{ Previous malignancy } \\
\hline no previous malignancy & 0.299 & 0.560 & 0.987 & 0.035 \\
\hline previous malignancy & 0.472 & 0.279 & 0.938 & 0.749 \\
\hline
\end{tabular}

doi:10.1371/joumal.pone.0155398.t004

[1.220-3.947]; $\mathrm{p}=0.009$; Table 5). This observation was next confirmed using log rank test $(\mathrm{p}=0.004$; Fig 4).

\section{Discussion}

Both the diagnostic and therapeutic management of incidentally discovered SPN depends on the evaluation of malignant probability. Therefore, risk factors such as smoking habits or work-related exposures need to be considered. Next, the exact description of shape and size is important. The bigger the nodule, the higher the chance for malignant transformation [10,2731]. Likewise, information regarding location [30], growth [32] and shape [33] should be respected, too. Predictive models such as the Mayo Clinic model (derived from chest X-rays with focus on age, smoking status, history of malignancy, SPN size, shape and location [27]) or computer-based calculation programs (e.g. http://chestx-ray.com/index.php/calculators/spncalculator) can facilitate risk stratification.

Although the number of elderly patients who require TAVI implantation is growing [24], there are neither evidence based recommendations nor clinical guidelines to decide upon the further therapeutic procedure of incidentally discovered SPN during pre-procedural TAVI evaluation. Hence, there is a growing demand for interdisciplinary decisions on priorities for further diagnostic versus therapeutic procedures in these patients.

To address this clinical problem, we evaluated pre-procedural CT scans of 484 patients with focus on solitary pulmonary nodules (SPN). SPN of at least $5 \mathrm{~mm}$ size were found in $18 \%$ in the initial study collective. This ratio corresponds well to other published studies, which reported incidence rates ranging from $3.5 \%$ to $28 \%$ [9,34-39].

To investigate the prognostic impact of SPN in patients who were under investigation for TAVI eligibility, we included only those 87 patients with incidentally discovered SPN $\geq 5 \mathrm{~mm}$ 
A)

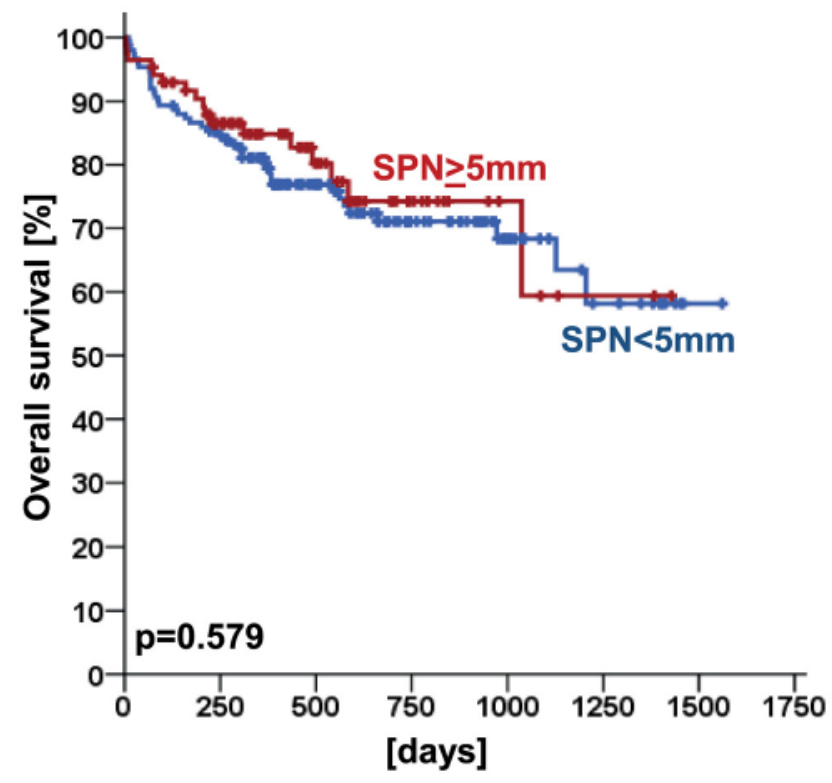

C)

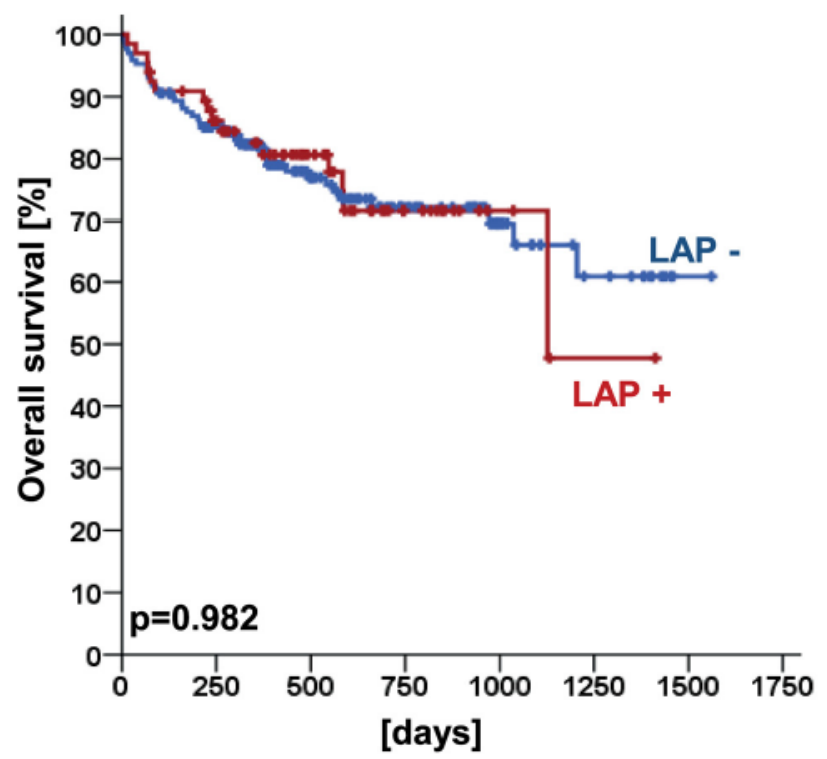

B)

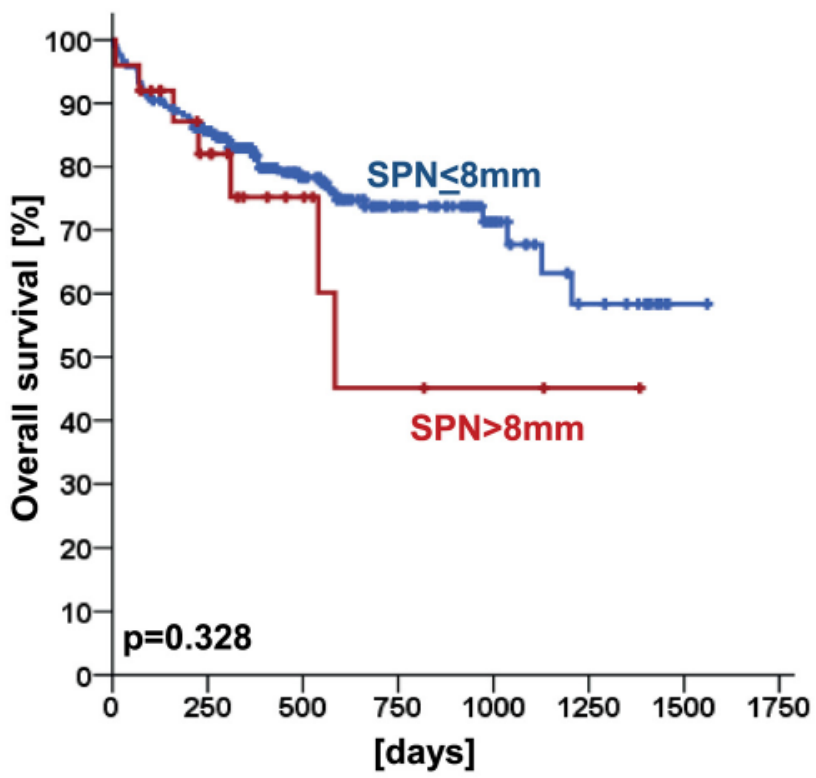

D)

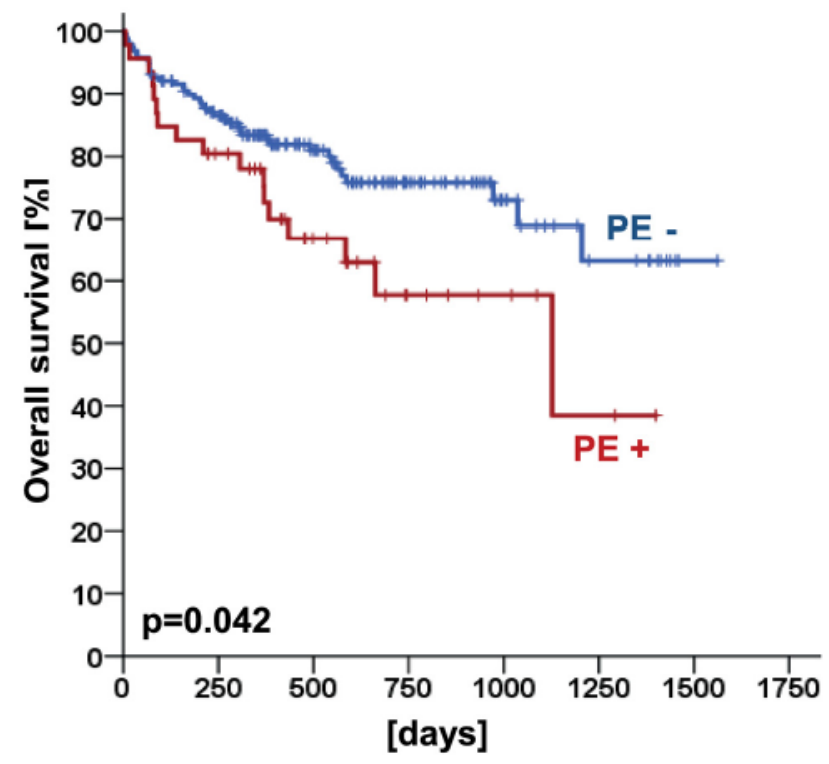

Fig 3. Prognostic impact of solitary pulmonary nodules (SPN), lymphadenopathy (LAP) and pleural effusions (PE) in patients under evaluation for TAVI ( $n=237$ patients). Kaplan Meier charts are given for SPN $\geq 5 \mathrm{~mm}(A)$, for $S P N>8 \mathrm{~mm}(B)$, for $L A P(C)$ and for PE (D).

doi:10.1371/joumal.pone.0155398.g003

and collected 150 control patients either without SPN or with SPN $<5 \mathrm{~mm}$. For all these patients ( $n=237$ patients in total) complete follow-up data were assigned and clinical correlations were studied. Besides, lymphadenopathy was found in $28 \%$ and pleural effusions in $19 \%$ of the investigated patients. Upon further diagnostics, $0.6 \%$ of the patients developed lung cancer. This ratio corresponds well to other reported ratios ranging from $0.3 \%$ to $1.2 \%$ [34$35,37,39]$. 
Table 5. Overall survival: Explanatory prognostic factors in a Cox proportional Hazards model for the selected study collective. Included variables: sex (male (ref.) vs. female), age ( $<80$ years (ref.) vs. $\geq 80$ years), LVEF (as a continuous variable), LVEF (LVEF < 45\% (ref.) vs. $\geq 45 \%$ ); previous malignancy (no previous (ref.) malignancy vs. previous malignancy); SPN (no SPN (ref.) vs. SPN $\geq 5 \mathrm{~mm}$ and all others (ref.) vs. $\mathrm{SPN}>8 \mathrm{~mm}$ ), lymphadenopathy (no lymphadenopathy (ref.) vs. lymphadenopathy) and pleural effusions (no pleural effusions (ref.) vs. pleural effusions).

\begin{tabular}{lcc}
\hline Identified prognostic factor & p-Value * & HR $^{\mathbf{1}}(95 \%$ Cl) \\
\hline LVEF & 0.009 & $2.194(1.220-3.947)$ \\
\hline
\end{tabular}

${ }^{1} \mathrm{HR}=$ hazard ratio: $\mathrm{HR}<1$ indicates improved survival.

${ }^{2} \mathrm{Cl}=$ confidence interval.

* $\mathrm{p}$ value indicates model improvement (likelihood ratio test).

doi:10.1371/joumal.pone.0155398.t005

With regard to clinical correlations, no relevant associations were found for SPN $\geq 5$. For smoking history however, a positive association with larger SPN of $>8 \mathrm{~mm}$ was observed. This association is also supported by another study group [9]. Besides, we found positive associations for lymphadenopathy with age and gender. To our knowledge, there are no other studies, which contribute to this observation. Potentially, this observation might only hint to a better general health status of women compared to men above the age of 80 years in our study collective. Hence, we also investigated the prognostic impact of gender on overall survival. However, for the investigated study collective we cannot report a relevant prognostic impact of gender on overall survival (data not shown).

Regarding prognosis, the incidence of SPN did not affect overall survival neither within the investigated entire study collective nor within clinical subgroups. In the univariate model, prognostic effects were found for pleural effusions in the full study collective and even stronger

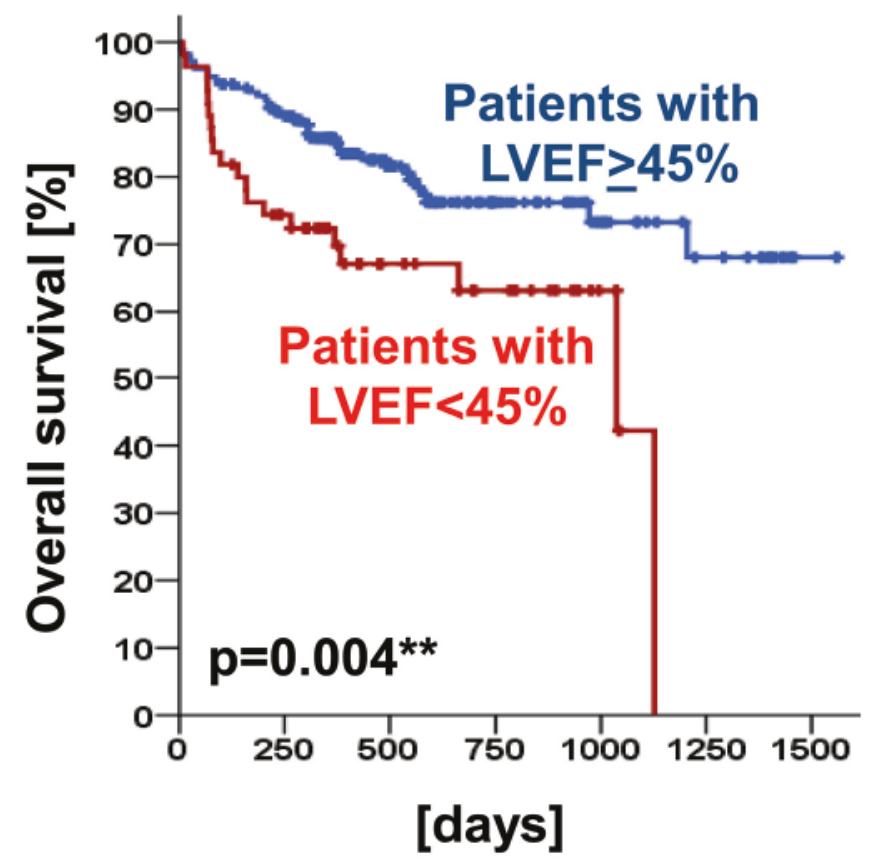

Fig 4. Prognostic impact of left ventricular ejection fraction (LVEF) in the full study collective $(p=0.004)$. Overall survival of those patients with a LVEF $\geq 45 \%$ was increased compared to those patients with a LVEF $<45 \%$.

doi:10.1371/joumal.pone.0155398.g004 
effects within the tested prognostic subgroups stratified for age, impaired FEV1 and a history of previous malignancies. In general, pleural effusions can be found in various clinical conditions. Besides, rheumatoid, infectious or malignant diseases [40], pleural effusions are often associated with cardiac failure [41]. Hence, the prognostic impact of pleural effusions might rather reflect cardiac failure in this population. In our study collective impaired LVEF was associated with pleural effusions (data not shown). This hypothesis can also be supported by the observed prognostic impact of LVEF both in the univariate and in the multivariate analysis.

With regard to this prognostic approach, further diagnostic procedures for incidentally discovered SPN delaying TAVI evaluation may not yield in improved prognosis for this patient collective and delay symptom amelioration and prognostic effects of TAVI. Similar to our approach, another research group focused on suspicious incidental radiological findings in 414 participants screened either for surgical aortic valve replacement or TAVI with dual-source CT scans [38]. According to their study, suspicious incidental radiological findings did not significantly influence further therapeutic decisions [odds ratio $(\mathrm{OR}) 1.14 ; \mathrm{P}=0.835$ ] or time to treatment (91 \pm 152 vs. $61 \pm 109$ days, respectively). Moreover, overall survival two years after decision to intervene did not differ significantly $(p>0.05,[38])$. The decision for treatment was made according to the guidelines for TAVI, which recommend the procedure only in patients with an estimated survival of 1 year at least [42]. Besides, decisions should be made up by interdisciplinary teams [42]. Our analysis indicates a need for more specific clinical recommendations or guidelines to decide on the further evaluation of patients at risk with newly detected SPN. Potentially, CT follow-up scans for patients with SPN in a good clinical status (i.e. NHYA I) might therefore be recommended after a period of six months. Otherwise, our results as well as other published results argue in favor of the notion, that standard guideline-approved procedures for SPN can be safely performed after TAVI. Besides its single-center nature, the retrospective study design and the interdisciplinary selection for TAVI intervention our study does have its limitations. However our results may be helpful in management of patients evaluated for TAVI who present with suspicious radiologic findings.

In conclusion, we were able to demonstrate, that the overall survival of those patients, who are under evaluation for TAVI was not affected by incidentally detected SPN. Thus, aggressive diagnostic approaches for incidentally discovered SPN during TAVI evaluation should not delay the treatment of aortic stenosis. Unless advanced thoracic malignancy is obvious, the well documented reduction of morbidity and mortality of severe symptomatic aortic stenosis by TAVI outweighs potentially harmful delays regarding further diagnostics. Standard guidelineapproved procedure for SPN can be safely performed after TAVI.

\section{Supporting Information}

S1 Table. Initial study collective. Baseline characteristics of all patients under TAVI evaluation $(n=484$ patients).

(DOCX)

\section{Acknowledgments}

NSCLC research in our laboratory is funded by the Innovative Medizinische Forschung Münster University (IMF: I-SC110818), Deutsche Krebshilfe e. V. (107888; 109666), Open Access Publication Fund of University of Muenster, and Wilhelm Sander-Stiftung (2009.041.1). W.E. B. is supported by Deutsche Forschungsgemeinschaft DFG EXC 1003 Cells in Motion-Cluster of Excellence. 


\section{Author Contributions}

Conceived and designed the experiments: LHS BV MM DG C. Schülke. Performed the experiments: LHS BV MM DG C. Schülke HB GK WEB. Analyzed the data: LHS BV MM DG C. Schülke MT. Contributed reagents/materials/analysis tools: LHS BV MM DG C. Schülke AK HB GK. Wrote the paper: LHS BV MM DG C. Schülke GK C. Schliemann TK RW HB WEB AK MT BB ABS.

\section{References}

1. Siegel R, Ma J, Zou Z, Jemal A. Cancer statistics, 2014. CA Cancer J Clin. 2014; 64(1):9-29. doi: 10. 3322/caac.21208 PMID: 24399786

2. Aberle DR, Adams AM, Berg CD, Black WC, Clapp JD, Fagerstrom RM, et al. Reduced lung cancer mortality with low-dose computed tomographic screening. N Engl J Med 2011; 365:395-409. doi: 10. 1056/NEJMoa1102873 PMID: 21714641

3. Stang A, Schuler M, Kowall B, Darwiche K, Kühl H, Jöckel KH. Lung Cancer Screening Using Low Dose CT Scanning in Germany. Dtsch Arztebl Int. 2015; 112(38):637-644. doi: 10.3238/arztebl.2015. 0637 PMID: 26429636

4. Aberle DR, DeMello S, Berg CD, Black WC, Brewer B, Church TR, et al.; National Lung Screening Trial Research Team. Results of the two incidence screenings in the National Lung Screening Trial. N Engl J Med. 2013; 369(10):920-931. doi: 10.1056/NEJMoa1208962 PMID: 24004119

5. Ost D, Fein AM, Feinsilver SH. Clinical practice. The solitary pulmonary nodule. N Engl J Med. 2003; 348(25):2535-2542. PMID: 12815140

6. Gould MK, Donington J, Lynch WR, Mazzone PJ, Midthun DE, Naidich DP, et al. Evaluation of individuals with pulmonary nodules: when is it lung cancer? Diagnosis and management of lung cancer, 3rd ed: American College of Chest Physicians evidence-based clinical practice guidelines. Chest. 2013; 143(5 Suppl):e93S-120S. doi: 10.1378/chest.12-2351 PMID: 23649456

7. Higgins GA, Shields TW, Keehn RJ. The solitary pulmonary nodule. Ten-year follow-up of veterans administration-armed forces cooperative study. Arch Surg. 1975; 110(5):570-575. PMID: 1093512

8. Seo JB, Im JG, Goo JM, Chung MJ, Kim MY. Atypical pulmonary metastases: spectrum of radiologic findings. Radiographics. 2001;21(2):403-417. PMID: 11259704

9. Gómez-Sáez N, González-Álvarez I, Vilar J, Hernández-Aguado I, Domingo ML, Lorente MF, et al. Prevalence and variables associated with solitary pulmonary nodules in a routine clinic-based population: across-sectional study. Eur Radiol. 2014; 24(9):2174-2182. doi: 10.1007/s00330-014-3249-z PMID: 24962823

10. MacMahon H, Austin JH, Gamsu G, Herold CJ, Jett JR, Naidich DP, et al.; Fleischner Society. Guidelines for management of small pulmonary nodules detected on CT scans: a statement from the Fleischner Society. Radiology. 2005; 237(2):395-400. PMID: 16244247

11. Vansteenkiste JF, Stroobants SS. PET scan in lung cancer: current recommendations and innovation. J Thorac Oncol. 2006; 1(1):71-73. PMID: 17409830

12. Mori $\mathrm{T}$, Nomori $\mathrm{H}$, Ikeda K, Kawanaka K, Shiraishi S, Katahira K, et al. Diffusion-weighted magnetic resonance imaging for diagnosing malignant pulmonary nodules/masses: comparison with positron emission tomography. J Thorac Oncol. 2008; 3(4):358-364. doi: 10.1097/JTO.0b013e318168d9ed PMID: 18379353

13. Grgic A, Yüksel Y, Gröschel A, Schäfers HJ, Sybrecht GW, Kirsch CM, et al. Risk stratification of solitary pulmonary nodules by means of PET using (18)F-fluorodeoxyglucose and SUV quantification. Eur J Nucl Med Mol Imaging. 2010 Jun; 37(6):1087-1094. doi: 10.1007/s00259-010-1387-3 PMID: 20140611

14. Herth F, Becker HD, Ernst A. Conventional vs endobronchial ultrasound-guided transbronchial needle aspiration: a randomized trial. Chest. 2004; 125(1):322-325. PMID: 14718460

15. Steinfort DP, Khor YH, Manser RL, Inving LB. Radial probe endobronchial ultrasound for the diagnosis of peripheral lung cancer: systematic review and meta-analysis. Eur Respir J. 2011; 37(4):902-910. doi: 10.1183/09031936.00075310 PMID: 20693253

16. Rivera MP, Mehta AC, Wahidi MM. Establishing the diagnosis of lung cancer: Diagnosis and management of lung cancer, 3rd ed: American College of Chest Physicians evidence-based clinical practice guidelines. Chest. 2013; 143(5 Suppl):e142S-65S. doi: 10.1378/chest.12-2353 PMID: 23649436

17. Lee SM, Park CM, Lee KH, Bahn YE, Kim JI, GooJM. C-arm cone-beam CT-guided percutaneous transthoracic needle biopsy of lung nodules: clinical experience in 1108 patients. Radiology. 2014; 271 (1):291-300. doi: 10.1148/radiol.13131265 PMID: 24475839 
18. Takeshita J, Masago K, Kato R, Hata A, Kaji R, Fujita S, et al. CT-guided fine-needle aspiration and core needle biopsies of pulmonary lesions: a single-center experience with 750 biopsies in Japan. AJR Am J Roentgenol. 2015; 204(1):29-34. doi: 10.2214/AJR.14.13151 PMID: 25539234

19. Allen MS, Deschamps C, Lee RE, Trastek VF, Daly RC, Pairolero PC. Video-assisted thoracoscopic stapled wedge excision for indeterminate pulmonary nodules. J Thorac Cardiovasc Surg. 1993; 106 (6):1048-1052. PMID: 8246537

20. Bernard A. Resection of pulmonary nodules using video-assisted thoracic surgery. The Thorax Group. Ann Thorac Surg. 1996; 61(1):202-204; discussion 204-5. PMID: 8561553

21. Naidich DP, Bankier AA, MacMahon H, Schaefer-Prokop CM, Pistolesi M, Goo JM, et al. Recommendations for the management of subsolid pulmonary nodules detected at CT: a statement from the Fleischner Society. Radiology. 2013; 266(1):304-317. doi: 10.1148/radiol.12120628 PMID: 23070270

22. lung $B$, Vahanian $A$. Epidemiology of valvular heart disease in the adult. Nat Rev Cardiol. 2011; 8 (3):162-172. doi: 10.1038/nrcardio.2010.202 PMID: 21263455

23. Généreux P, Head SJ, Wood DA, Kodali SK, Williams MR, Paradis JM, et al. Transcatheter aortic valve implantation 10 year anniversary: review of current evidence and clinical implications. Eur Heart J. 2012; 33(19):2388-2398. doi: 10.1093/eurheartj/ehs220 PMID: 22851654

24. Alsara $\mathrm{O}$, Alsarah $\mathrm{A}$, Laird-Fick $\mathrm{H}$. Advanced age and the clinical outcomes of transcatheter aortic valve implantation. J Geriatr Cardiol. 2014; 11(2):163-170. doi: 10.3969/j.issn.1671-5411.2014.02.004 PMID: 25009568

25. Vahanian A, Alfieri O, Andreotti F, Antunes MJ, Barón-Esquivias G, Baumgartner $\mathrm{H}$, et al. Joint Task Force on the Management of Valvular Heart Disease of the European Society of Cardiology (ESC); European Association for Cardio-Thoracic Surgery (EACTS), Guidelines on the management of valvular heart disease (version 2012). Eur Heart J. 2012; 33(19):2451-2496. doi: 10.1093/eurheartj/ehs109 PMID: 23474606

26. Webb J, Cribier A. Percutaneous transarterial aortic valve implantation: what do we know? Eur Heart J. 2011; 32(2):140-147. doi: 10.1093/eurheartj/ehq453 PMID: 21131653

27. Swensen SJ, Silverstein MD, Ilstrup DM, Schleck CD, Edell ES. The probability of malignancy in solitary pulmonary nodules. Application to small radiologically indeterminate nodules. Arch Intern Med. 1997;28; 157(8):849-855. PMID: 9129544

28. Gohagan J, Marcus $P$, Fagerstrom R, Pinsky P, Kramer B, Prorok P, et al. Baseline findings of a randomized feasibility trial of lung cancer screening with spiral CT scan vs chest radiograph: the Lung Screening Study of the National Cancer Institute. Chest. 2004; 126(1):114-121. PMID: 15249451

29. Gould MK, Ananth L, Barnett PG. A clinical model to estimate the pretest probability of lung cancer in patients with solitary pulmonary nodules. Veterans Affairs SNAP Cooperative Study Group. Chest. 2007; 131 (2):383-388. PMID: 17296637

30. McWilliams A, Tammemagi MC, Mayo JR, Roberts H, Liu G, Soghrati K, et al. Probability of cancer in pulmonary nodules detected on first screening CT. N Engl J Med. 2013; 369(10):910-919. doi: 10. 1056/NEJMoa1214726 PMID: 24004118

31. Mehta HJ, Ravenel JG, Shaftman SR, Tanner NT, Paoletti L, Taylor KK, et al. The utility of nodule volume in the context of malignancy prediction for small pulmonary nodules. Chest. 2014; 145(3):464472. doi: 10.1378/chest. 13-0708 PMID: 23949741

32. Song YS, Park CM, Park SJ, Lee SM, Jeon YK, Goo JM. Volume and mass doubling times of persistent pulmonary subsolid nodules detected in patients without known malignancy. Radiology. 2014; 273 (1):276-284. doi: 10.1148/radiol.14132324 PMID: 24927472

33. Zerhouni EA, Stitik FP, Siegelman SS, Naidich DP, Sagel SS, Proto AV, et al. CT of the pulmonary nodule: a cooperative study. Radiology. 1986; 160(2):319-327. PMID: 3726107

34. Onuma Y, Tanabe K, Nakazawa G, Aoki J, Nakajima H, Ibukuro K, et al. Noncardiac findings in cardiac imaging with multidetector computed tomography. J Am Coll Cardiol 2006; 48:402-406. PMID: 16843193

35. Mueller J, Jeudy J, Poston R, White CS. Cardiac CT angiography after coronary bypass surgery: prevalence of incidental findings. Am J Roentgenol 2007; 189:414-419. PMID: 17646469

36. Burt JR, Iribarren C, Fair JM, Norton LC, Mahbouba M, Rubin GD, et al. Incidental findings on cardiac multidetector row computed tomography among healthy older adults: prevalence and clinical correlates. Arch Intern Med 2008; 168:756-761. doi: 10.1001/archinte.168.7.756 PMID: 18413559

37. Machaalany J, Yam Y, Ruddy TD, Abraham A, Chen L, Beanlands RS, et al. Potential clinical and economic consequences of noncardiac incidental findings on cardiac computed tomography. J Am Coll Cardiol. 2009; 54(16):1533-1541. doi: 10.1016/j.jacc.2009.06.026 PMID: 19815125

38. Stachon P, Kaier K, Milde S, Pache G, Sorg S, Siepe M, et al. Two-year survival of patients screened for transcatheter aortic valve replacement with potentially malignant incidental findings in initial body 
computed tomography. Eur Heart J Cardiovasc Imaging. 2015; 16(7):731-737. doi: 10.1093/ehjci jev055 PMID: 25759083

39. Haller S, Kaiser C, Buser P, Bremerich J. Coronary artery imaging with contrast-enhanced MDCT: extracardiac findings. Am J Roentgenol 2006;187:105-110. PMID: 16794163

40. Villena Garrido V, Cases Viedma E, Fernández Villar A, de Pablo Gafas A, Pérez Rodríguez E, Porcel Pérez JM, et al. Recommendations of diagnosis and treatment of pleural effusion. Update. Arch Bronconeumol. 2014; 50(6):235-249. doi: 10.1016/J.arbres.2014.01.016 PMID: 24698396

41. Porcel JM. Pleural effusions from congestive heart failure. Semin Respir Crit Care Med. 2010; 31 (6):689-697. doi: 10.1055/s-0030-1269828 PMID: 21213200

42. Nishimura RA, Otto CM, Bonow RO, Carabello BA, Erwin JP 3rd, Guyton RA, et al. 2014 AHA/ACC guideline for the management of patients with valvular heart disease: executive summary: a report of the american college of cardiology/American heart association task force on practice guidelines. J Am Coll Cardiol. 2014; 63(22):2438-2488. doi: 10.1016/j.jacc.2014.02.537 PMID: 24603192 